\title{
Uma plataforma para autoria de jogos digitais terapêuticos que apoiam o tratamento de crianças com câncer
}

\author{
Kamila Rios da Hora Rodrigues ${ }^{1}$, Paula Maia de Souza ${ }^{2}$, Thiago Yonamine¹, Ludmila Maschio Marques ${ }^{1}$, Vânia \\ Paula de Almeida Neris ${ }^{2}$ \\ Departamento de Computação - Universidade Federal de São Carlos (UFSCar) - São Carlos, São Paulo, Brasil \\ $1\{$ kamila.rios, thyonamine1, ludmilammarques\}@gmail.com \\ 2 paula.souza, vania.neris\}@dc.ufscar.br
}

\begin{abstract}
RESUMO
Jogos terapêuticos visam apoiar os tratamentos de reabilitação e ajudar os pacientes a compreender, se motivar e persistir nas práticas terapêuticas. Este trabalho descreve uma plataforma para a autoria de jogos digitais configurados por profissionais de saúde para conduzir atividades terapêuticas com seus pacientes e os respectivos cuidadores. A plataforma dispõe de uma interface Web para a autoria dos jogos e visualização dos relatórios, bem como um aplicativo móvel para exibir os jogos criados para os pacientes. Técnicas do Design Participativo foram utilizadas durante o desenvolvimento para engajar todas as partes interessadas. Feedbacks iniciais apontam para a adesão dos profissionais à solução criada.
\end{abstract}

\section{PALAVRAS-CHAVE}

Jogos Digitais Terapêuticos, Câncer Infantil, Interface de Autoria.

\section{Introdução}

Jogos digitais são sistemas de software interativos usados para o lazer, entretenimento e, cada vez mais, como ferramenta para a educação e para a saúde [2]. Mader et al. [3] definem jogos digitais terapêuticos como sendo aqueles jogos digitais que produzem um efeito terapêutico direto e pretendido sobre os jogadores (pacientes), sendo que esse efeito terapêutico pode aliviar, melhorar ou até mesmo curar a condição específica dos pacientes. Os jogos digitais terapêuticos conseguem esconder a carga das tarefas terapêuticas em um mundo de fantasia, potencializando o poder motivacional e a adesão à terapia.

Apesar do aumento no uso desse tipo de jogos nos últimos anos [4], a pesquisa sobre o desenvolvimento desses sistemas na área da Computação ainda é incipiente. No Brasil, poucos jogos foram desenvolvidos e sem o apoio de profissionais da área da saúde. $\mathrm{O}$ Jogo da Escolha [6] e Dermaplay [1] são alguns exemplos de

\footnotetext{
Permission to reproduce or distribute, in whole or in part, material extracted from this work, verbatim, adapted or remixed, as well as the creation or production from the content of such work, is granted without fee for non-commercial use, provided that the original work is properly credited. IHC 2019 - TRILHA POSTERES E DEMONSTRAÇÕES, Outubro 21-25, 2019, Vitória, Brasil. In Anais Estendidos do XVIII Simpósio Brasileiro sobre Fatores Humanos em Sistemas Computacionais. Porto Alegre: SBC.

(C) 2019 by the author(s), in accordance with the terms of the Creative Commons Attribution-NonCommercial 4.0 International Public License (CC BY-NC 4.0).
}

jogos digitais terapêuticos desenvolvidos por pesquisadores brasileiros. Há, portanto, demanda por novos títulos, em particular, no contexto do cuidador e da criança com câncer.

O cenário complexo, no qual o jogo terapêutico deste projeto está inserido exige uma equipe multidisciplinar e uma visão abrangente para o desenvolvimento do mesmo. Neste sentido, o projeto contou com apoio de profissionais de saúde de um hospital especializado no tratamento de câncer infantil. Com esse apoio foi possível desenvolver uma plataforma Web que permite a autoria de jogos terapêuticos por parte dos profissionais e que são posteriormente utilizados por crianças e seus cuidadores em seus dispositivos móveis durante o tratamento no hospital. Além de entreter, os jogos têm os seguintes objetivos terapêuticos: a) esclarecer sobre a doença e o tratamento, b) estimular o otimismo e a esperança, c) minimizar efeitos superprotetores dos cuidadores. Esses objetivos foram identificados durante práticas participativas para clarificação do problema de design realizada em conjunto com os profissionais do hospital.

Nas seções a seguir a metodologia adotada no projeto é descrita, bem como as interfaces produzidas e o andamento atual dos trabalhos.

\section{Metodologia}

A plataforma aqui descrita foi desenvolvida com o apoio de uma abordagem para o design de jogos digitais terapêuticos [5] que dispõe de 4 etapas: Clarificação do Problema de Design, Modelagem da Interação, Materialização do Design e Avaliação. Os profissionais do hospital participaram de todas as etapas, mas foram decisivos nas etapas de design e avaliação da plataforma que é composta por uma interface Web e um aplicativo móvel para interação com o jogo.

No sistema da Web, o profissional (e.g., terapeuta, pediatra, nutricionista) pode cadastrar seus pacientes e os familiares (cuidadores), e criar projetos de jogos, bem como configurar que tipo de conteúdo (e.g. imagens, mensagens de feedback) deve ser incluído no jogo (vide recorte disponibilizado na Figura 1). É importante ressaltar que as mídias podem ser escolhidas pelos profissionais no momento da autoria. Os objetivos terapêuticos (esperança, otimismo, esclarecimento da condição patológica) podem ser trabalhados por meio de três mecânicas de jogo previamente disponibilizadas na interface Web: Puzzle (Encaixe), Quiz (Perguntas) e Plataforma (Comidas), conforme ilustrado na Figura 2. 

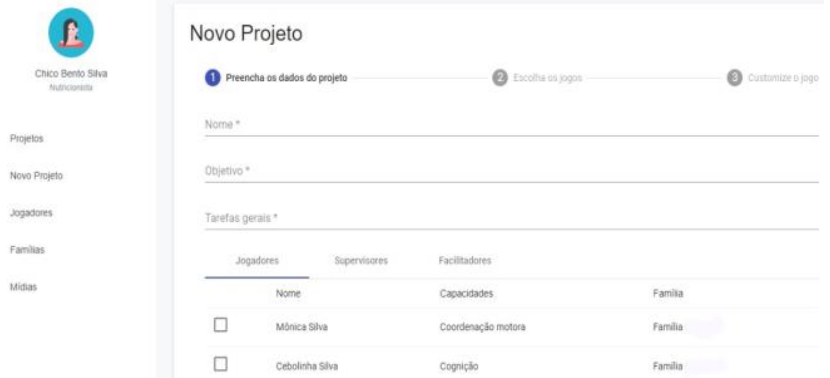

Figura 1: Interface Web para a criação de um projeto.

Os jogadores acessam o jogo por meio de um aplicativo mobile, usando login e senha. Enquanto crianças e cuidadores jogam, as suas ações são capturadas, armazenadas e enviadas ao sistema Web, que irá gerar relatórios de desempenho dos jogadores para os profissionais, e esses podem então realizar procedimentos de intervenção durante o tratamento.

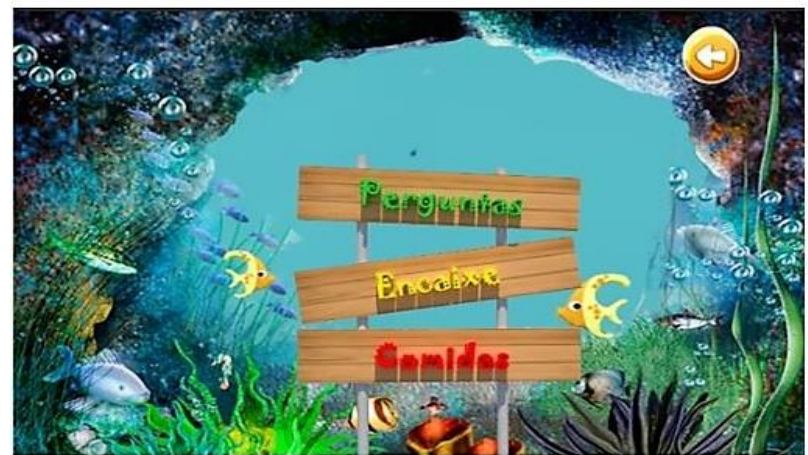

Figura 2: Tela de escolha das mecânicas do jogo configuradas previamente no sistema Web.

O jogo foi desenvolvido utilizando a Game Engine Unity e a linguagem de programação C\#. O sistema Web foi implementado utilizando a linguagem de programação Python, os frameworks Django e Angular 6 e o sistema de gerenciamento de banco de dados MySQL. O jogo será utilizado pelos profissionais da saúde com as crianças do Hospital para avaliação da resposta emocional e avaliação dos resultados do jogo em relação aos objetivos terapêuticos. Essa próxima etapa aguarda autorização do Comitê de Ética em Pesquisa para ser conduzida.

A Figura 3a ilustra uma das telas configuradas por um nutricionista com a mecânica Plataforma. Nesse jogo a criança deve escolher que alimentos ele pode "comer" durante o tratamento.

Ao fim de cada fase, um feedback sonoro e com estrelas é disponibilizado como reforço positivo. Na intenção de identificar como o jogador está se sentindo após jogar a fase, é perguntado a ele como está, sendo que ele deve responder em uma escala de 5 estrelas (Figura 3b).

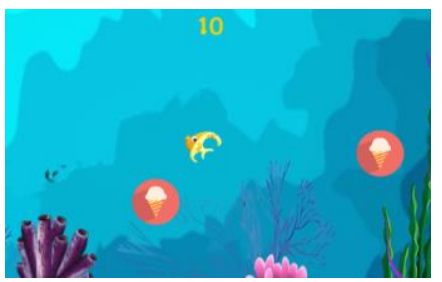

Figura 3a: Tela do jogo de plataforma.
Figura 3b: Tela dofeedback ao completar os objetivos da fase.

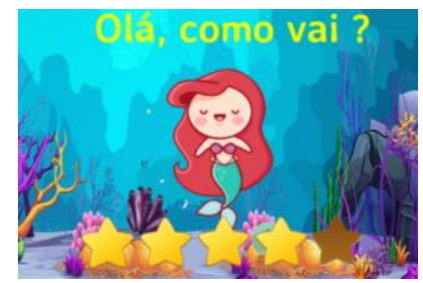

\section{Conclusão}

Este trabalho é fruto de projetos de extensão que têm buscado engajar a universidade e a comunidade, trazendo benefícios para ambas. A possibilidade de criar objetos de interação no formato de jogos permite que profissionais da saúde possam criar soluções para seus pacientes a depender de cada necessidade, assim como permite a coleta de dados de forma remota e direcionada para cada indivíduo. Uma vez que é colaborativo, ou seja, familiares também podem ser inseridos no jogo, esses atores também são instruídos e participam do processo terapêutico.

Os autores desta proposta acreditam que os jogos podem trazer mais leveza ao tratamento, entretendo $\mathrm{e}$ fornecendo $\mathrm{o}$ conhecimento que cada profissional deseja passar ao seu paciente/cuidador. O feedback dos profissionais que apoiaram as etapas de design e avaliação encorajam este grupo a realizar o constante aperfeiçoamento da plataforma, de modo que novas mecânicas possam ser inseridas e outras funcionalidades permitam aos profissionais realizar a autoria de jogos cada vez mais personalizados e efetivos aos tratamentos.

\section{AGRADECIMENTOS}

O presente trabalho foi realizado com apoio da Coordenação de Aperfeiçoamento de Pessoal de Nível Superior - Brasil (CAPES) Código de Financiamento 001.

\section{REFERÊNCIAS}

[1] Fontes Neto, P. de T. L. (2011). Desenvolvimento de um jogo educativo/terapêutico no auxílio ao tratamento da dermatite atópica. Porto Alegre: Universidade Federal do Rio Grande do Sul..

[2] Grammenos, D.; Savidis, A.; Stephanidis, C. (2009). Designing universally accessible games. Magazine Computers in Entertainment (CIE) - Special Issue: Media Arts and Games, 2009, v. 7, p. 29.

[3] Mader S.; Levieux G. and Natkin S. 2016. A game design method for therapeutic games. In: 8th International Conference on Games and Virtual Worlds for Serious Applications (VS-GAMES). p.1-8.

[4] Matthews, M.; Coyle, D. (2010). Therapeutic Computer Games. In the Use of Technology in Mental Health: Applications, Ethics and Practice. Anthony. [S.1.]: Charles C Thomas Pub Ltd, 2010. p.134-142.

[5] Souza, P. M.; Rodrigues, K. R. H.; Garcia, F. E.; Neris, V. P. A. Towards a Semiotic-Based Approach to the Design of Therapeutic Digital Games. In: Liu, K.; Nakata, K.; Li, W.; Baranauskas, C. (Ed.). Digitalisation, Innovation, and Transformation. [S.l.]: Springer International Publishing, 2018. (IFIP Advances in Information and Communication Technology), p. 53-62. ISBN 978-3-31994541-5.

[6] Williams, A. V. (2011) Desenvolvimento e Avaliação do Efeito de um Jogo Terapêutico para Jovens Usuários de Drogas. Porto Alegre: Universidade Federal do Rio Grande do Sul, 2011. 